\title{
Two Cases of Hepatocellular Carcinoma Occurring Immediately after Direct-acting Antiviral Agents against Hepatitis C Virus
}

\author{
Norihiro Nishijima, Akihiro Nasu, Toru Kimura and Yukio Osaki
}

\begin{abstract}
:
We experienced two cases of hepatocellular carcinoma (HCC) occurring immediately after treatment with direct-acting antiviral agents (DAAs). Case 1 was a 75 -year-old woman in whom HCC was detected immediately after completion of DAA treatment. Case 2 was a 75-year-old woman who had a hypovascular nodule in liver. The hypovascular nodule became hypervascular without enlargement of the nodule size immediately after DAA treatment completion. Although the association between DAA treatment and hepatocarcinogenesis is unknown, sufficient surveillance after achieving a sustained viral response is required, as a large number of patients at a high risk of hepatocarcinogenesis are treated with DAAs.
\end{abstract}

Key words: hepatocellular carcinoma, direct-acting antiviral agents, hepatitis $\mathrm{C}$ virus, sustained virological response

(Intern Med 58: 225-231, 2019)

(DOI: 10.2169/internalmedicine.0712-17)

\section{Introduction}

Treatment with direct-acting antiviral agents (DAAs) against hepatitis $\mathrm{C}$ virus (HCV) achieves an extremely high sustained virological response (SVR) rate. Although DAA treatment is expected to prevent the occurrence of $\mathrm{HCV}$ related hepatocellular carcinoma (HCC), an unanticipated high rate of HCC occurrence or recurrence following DAA treatment has recently been reported $(1,2)$. Therefore, whether DAA treatment prevents or promotes hepatocarcinogenesis is controversial.

We herein report one case of HCC occurring immediately after DAA treatment despite the absence of evidence of HCC before treatment and one case of HCC in which a hypovascular nodule that had not changed for 10 years became hypervascular immediately after DAA treatment.

\section{Case Reports}

\section{Case 1}

The patient was a 75-year-old woman who had been treated for hepatitis $\mathrm{C}$ infection with ursodeoxycholic acid for 22 years at our hospital. She had not received interferon (IFN) treatment because of concerns about the side effects. She had no history of smoking or alcohol consumption. Her height was $145.0 \mathrm{~cm}$, weight $50.8 \mathrm{~kg}$, and body mass index $24.2 \mathrm{~kg} / \mathrm{m}^{2}$. The laboratory data on admission are shown in Table 1 . Her HCV genotype was $1 b$.

Direct sequencing and a cycling-probe analysis (3) did not reveal variants associated with L31 or Y93 in the nonstructural protein 5A (NS5A) region of the HCV RNA. Her serum level of Mac-2 Binding Protein Glycosylation isomer (M2BPGi) (4) was 3.39(2+), suggesting the progression of liver fibrosis. She had a Child-Pugh class A (5 points) liver function.

She was treated for 12 weeks with ombitasvir/paritaprevir/ ritonavir. After the initiation of DAA treatment, the $\mathrm{HCV}$

Department of Gastroenterology and Hepatology, Osaka Red Cross Hospital, Japan

Received: December 25, 2017; Accepted: June 25, 2018; Advance Publication by J-STAGE: August 24, 2018

Correspondence to Dr. Norihiro Nishijima, nnishijima14@gmail.com 
Table 1. Laboratory Data on Admission of Case 1.

\begin{tabular}{lrlc}
\hline White blood cells & $3,780 / \mu \mathrm{L}$ & Glucose & $107 \mathrm{mg} / \mathrm{dL}$ \\
Hemoglobin & $14.1 \mathrm{~g} / \mathrm{dL}$ & Prothrombin time & $96 \%$ \\
Platelets & $102,000 / \mu \mathrm{L}$ & Activated partial prothrombin time & $25 \mathrm{sec}$ \\
Total protein & $7.9 \mathrm{~g} / \mathrm{dL}$ & Fibrinogen & $281 \mathrm{mg} / \mathrm{dL}$ \\
Albumin & $3.7 \mathrm{~g} / \mathrm{dL}$ & Mac-2 Binding Protein Glycosylation isomer & $3.39(2+)$ \\
Total bilirubin & $0.8 \mathrm{mg} / \mathrm{dL}$ & Hepatitis C virus RNA & $6.3 \mathrm{LogIU} / \mathrm{mL}$ \\
Asparate aminotransferase & $77 \mathrm{IU} / \mathrm{L}$ & Hepatitis C virus genotype & $1 \mathrm{~b}$ \\
Alanine aminotransferase & $56 \mathrm{IU} / \mathrm{L}$ & L31 & wild \\
Alkaline phosphatase & $428 \mathrm{IU} / \mathrm{L}$ & Y93 & wild \\
$\gamma$-glutamyltransferase & $22 \mathrm{IU} / \mathrm{L}$ & $\alpha$-fetoprotein & $5.4 \mathrm{ng} / \mathrm{mL}$ \\
Lactate dehydrogenase & $225 \mathrm{IU} / \mathrm{L}$ & $\alpha$-fetoprotein-L3 & $<0.5 \%$ \\
Cholinesterase & $235 \mathrm{IU} / \mathrm{L}$ & Des- $\gamma$-carboxyprothrombin & $10 \mathrm{mAU} / \mathrm{mL}$ \\
Blood urea nitrogen & $19.8 \mathrm{mg} / \mathrm{dL}$ & & \\
Creatinine & $0.87 \mathrm{mg} / \mathrm{dL}$ & & \\
C-reactive protein & $<0.2 \mathrm{mg} / \mathrm{dL}$ & & \\
\hline
\end{tabular}

\section{$\mathrm{OBV} / \mathrm{PTV} / \mathrm{r}$}

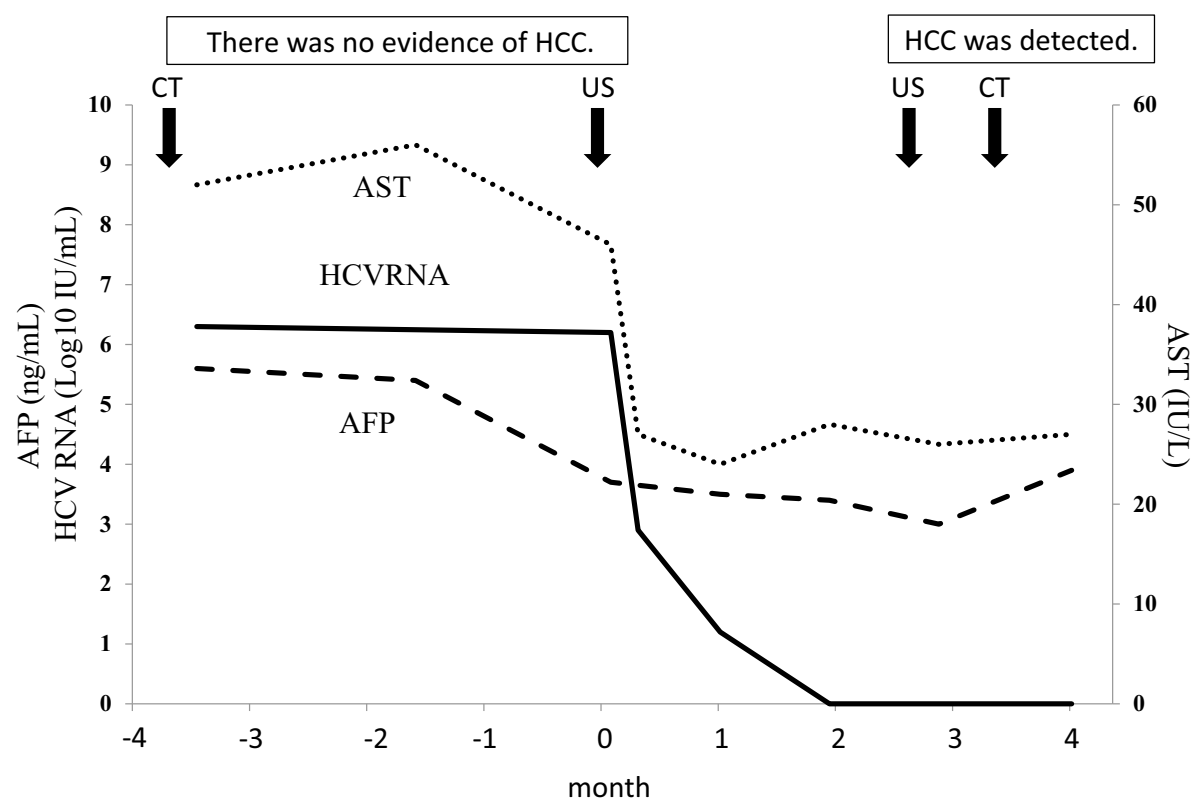

Figure 1. Clinical course of Case 1. OBV/PTV/r: ombitasvir/paritaprevir/ritonavir

RNA rapidly became undetectable, and the serum level of alanine aminotransferase (ALT) decreased to within the normal range (Fig. 1). Just before the completion of the DAA treatment, however, abdominal ultrasonography (US) revealed a hyperechoic nodule with a hypoechoic halo, $1.7 \mathrm{~cm}$ in diameter, in liver segment 6 (Fig. 2b). The lesion showed enhancement in the early phase and subsequent washout in the delayed phase of dynamic computed tomography (CT), suggesting that HCC occurred immediately after DAA treatment (Fig. 3c and d). Retrospectively, there was no evidence of HCC on abdominal ultrasonography one month before (Fig. 2a) or on dynamic CT four months before the initiation of DAA treatment (Fig. 3a and b). She underwent radiofrequency ablation of the lesion and has survived without recurrence for 17 months.

\section{Case 2}

The patient was a 75-year-old woman who had been treated for hepatitis $\mathrm{C}$ infection with ursodeoxycholic acid for 12 years at our hospital. She had not received IFN treatment because of concerns regarding the side effects. Two years after her first admission, gadolinium ethoxybenzyl diethylenetriamine pentaacetic acid (Gd-EOB-DTPA) enhanced magnetic resonance imaging (MRI) revealed a hypovascular nodule, $1.0 \mathrm{~cm}$ in diameter, in liver segment 6 with low intensity in both the arterial and hepatobiliary phases (Fig. 4a and b) that did not change for 10 years. She had no history of smoking or alcohol consumption. Her height was $150.6 \mathrm{~cm}$, weight $47.8 \mathrm{~kg}$, and body mass index $21.0 \mathrm{~kg} / \mathrm{m}^{2}$. The laboratory data on admission are shown in 
a

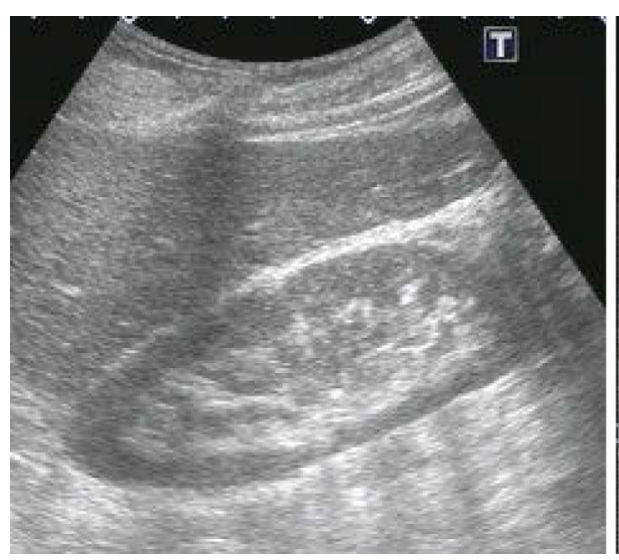

b

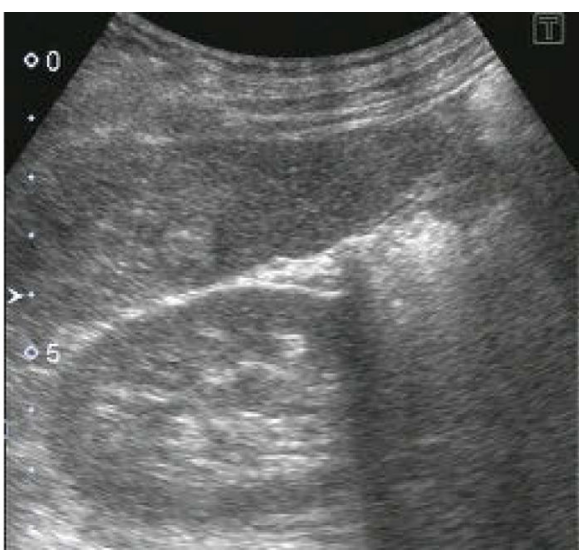

Figure 2. There was no evidence of HCC on US at one month before the initiation of DAA treatment (a). US revealed a hyperechoic nodule with a hypoechoic halo, $1.7 \mathrm{~cm}$ in diameter, in liver segment 6 just before the completion of DAA treatment (b).

a

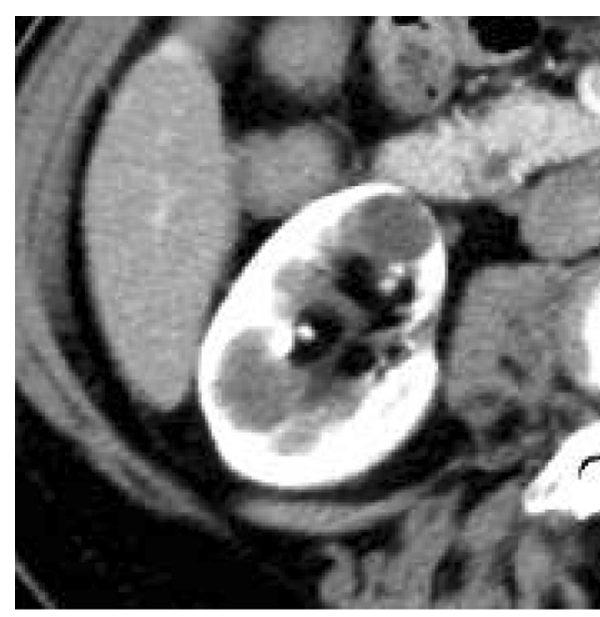

C

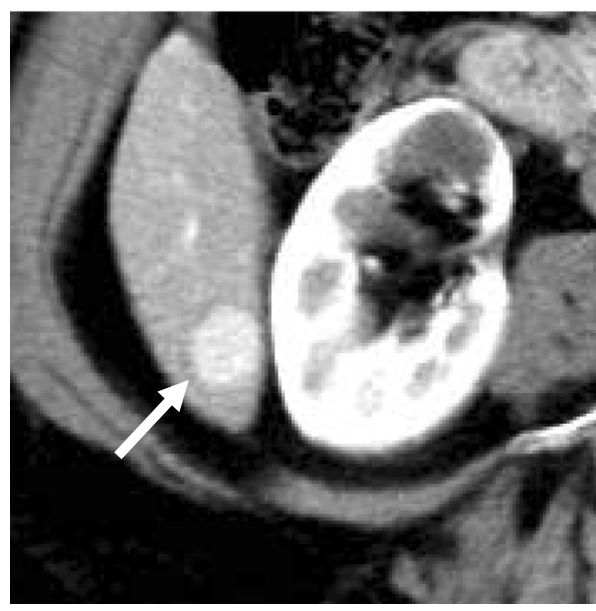

b

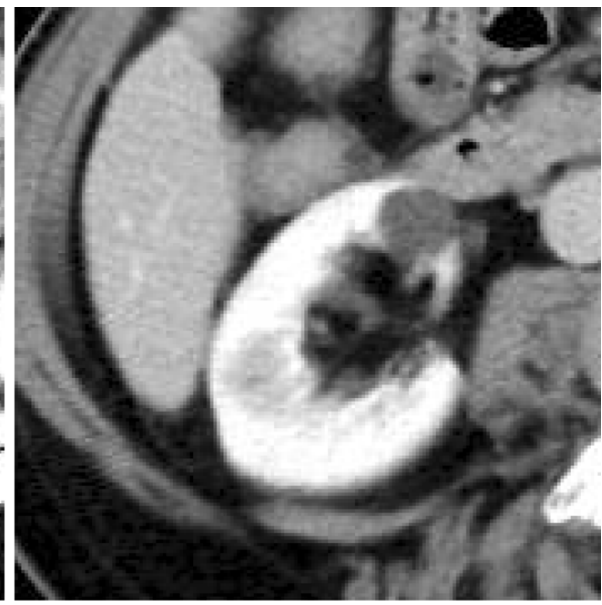

d

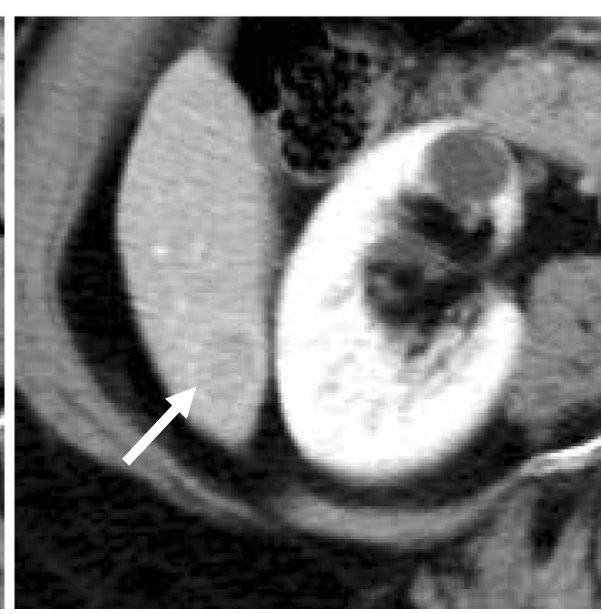

Figure 3. There was no evidence of HCC on dynamic CT in the early phase (a) or delayed phase (b) at four months before the initiation of DAA treatment. Dynamic CT revealed a lesion, $1.7 \mathrm{~cm}$ in diameter, in liver segment 6, showing enhancement in the early phase (c) and subsequent washout in the delayed phase (d) immediately after DAA treatment. 
Table 2. Laboratory Data on Admission of Case 2.

\begin{tabular}{lrlc}
\hline White blood cells & $4,010 / \mu \mathrm{L}$ & Glucose & $89 \mathrm{mg} / \mathrm{dL}$ \\
Hemoglobin & $14.0 \mathrm{~g} / \mathrm{dL}$ & Prothrombin time & $86 \%$ \\
Platelets & $113,000 / \mu \mathrm{L}$ & Activated partial prothrombin time & $29.8 \mathrm{sec}$ \\
Total protein & $7.8 \mathrm{~g} / \mathrm{dL}$ & Fibrinogen & $240 \mathrm{mg} / \mathrm{dL}$ \\
Albumin & $3.7 \mathrm{~g} / \mathrm{dL}$ & Mac-2 Binding Protein Glycosylation isomer & $6.80(2+)$ \\
Total bilirubin & $1.3 \mathrm{mg} / \mathrm{dL}$ & Hepatitis C virus RNA & $6.6 \mathrm{LogIU} / \mathrm{mL}$ \\
Asparate aminotransferase & $82 \mathrm{IU} / \mathrm{L}$ & Hepatitis C virus genotype & $1 \mathrm{~b}$ \\
Alanine aminotransferase & $82 \mathrm{IU} / \mathrm{L}$ & L31 & wild \\
Alkaline phosphatase & $644 \mathrm{IU} / \mathrm{L}$ & Y93 & mixed \\
$\gamma$-glutamyltransferase & $36 \mathrm{IU} / \mathrm{L}$ & Y93 wild & $10 \%$ \\
Lactate dehydrogenase & $283 \mathrm{IU} / \mathrm{L}$ & Y93 mutant & $90 \%$ \\
Cholinesterase & $230 \mathrm{IU} / \mathrm{L}$ & $\alpha$-fetoprotein & $66.4 \mathrm{ng} / \mathrm{mL}$ \\
Blood urea nitrogen & $23.4 \mathrm{mg} / \mathrm{dL}$ & $\alpha$-fetoprotein-L3 & $<0.5 \%$ \\
Creatinine & $0.65 \mathrm{mg} / \mathrm{dL}$ & Des- $\gamma$-carboxyprothrombin & $11 \mathrm{mAU} / \mathrm{mL}$ \\
C-reactive protein & $<0.2 \mathrm{mg} / \mathrm{dL}$ & & \\
\hline
\end{tabular}

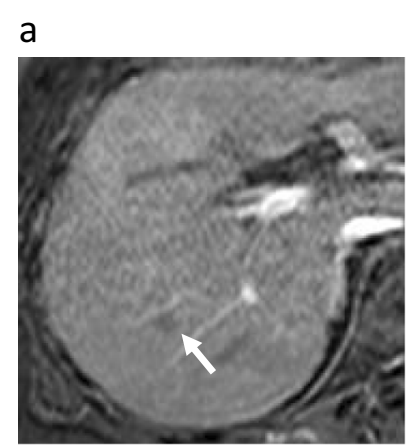

\section{b}

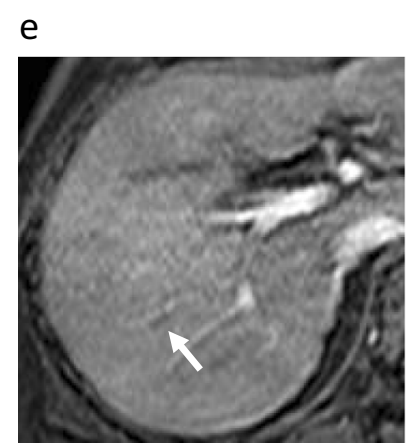

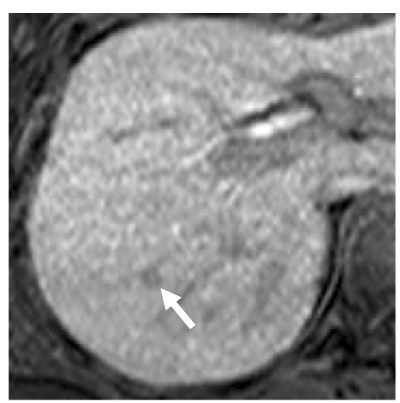

c

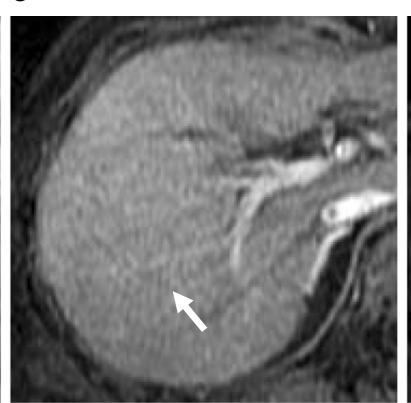

$f$

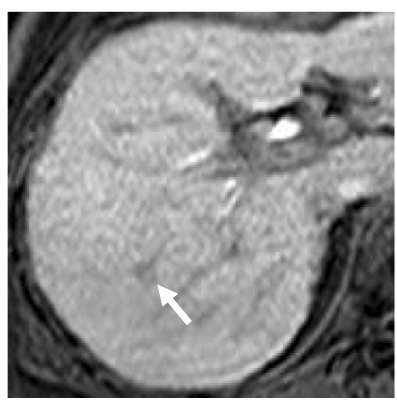

g

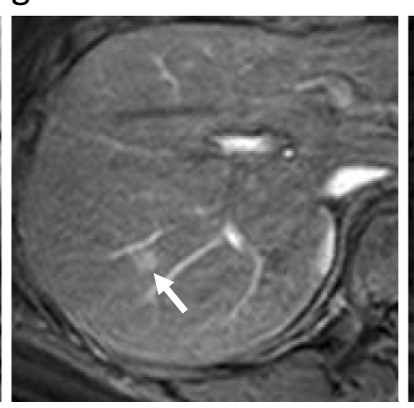

d

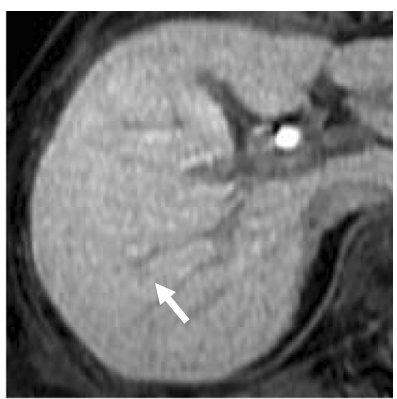

h

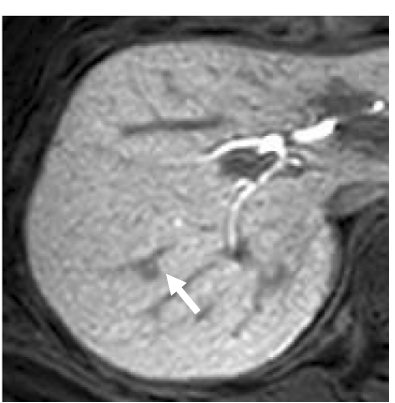

Figure 4. Gd-EOB-DTPA-enhanced MRI revealed a lesion, $1.0 \mathrm{~cm}$ in diameter, in liver segment 6, showing low intensity in the arterial (a) and hepatobiliary phases (b) 10 years before DAA treatment. The intensity of the lesion was unchanged in the arterial (c) and hepatobiliary phases (d) three months before the initiation of DAA treatment and in the arterial (e) and hepatobiliary phases (f) during the course of DAA treatment. The lesion showed high intensity in the arterial phase (g) and low intensity in the hepatobiliary phase (h) three months after the completion of DAA treatment.

Table 2. Her HCV genotype was $1 \mathrm{~b}$.

Direct sequencing and a cycling-probe analysis (3) did not show an L31 mutation in the NS5A region of $\mathrm{HCV}$ RNA. Direct sequencing of Y93, however, revealed the mixed type (Y93Y/H), and a cycling-probe analysis revealed $10 \%$ Y93 wild strain and $90 \%$ Y93H mutant strain. Her serum level of M2BPGi was $6.80(2+)$, suggesting the progression of liver fibrosis. She had a Child-Pugh class A (5 points) liver function.

She was treated for 12 weeks with ledipasvir/sofosbuvir.
After the initiation of DAA treatment, the HCV RNA rapidly became undetectable, and the serum level of ALT decreased to within the normal range (Fig. 5). Three months after completion of the DAA treatment, however, the hypovascular nodule became hypervascular without enlargement. The lesion showed high intensity in the arterial phase and low intensity in the hepatobiliary phase of Gd-EOBDTPA-enhanced MRI (Fig. 4g and h). Retrospectively, the lesion had been a hypovascular nodule without enlargement for 10 years at the first indication (Fig. 4a and b), 3 months 


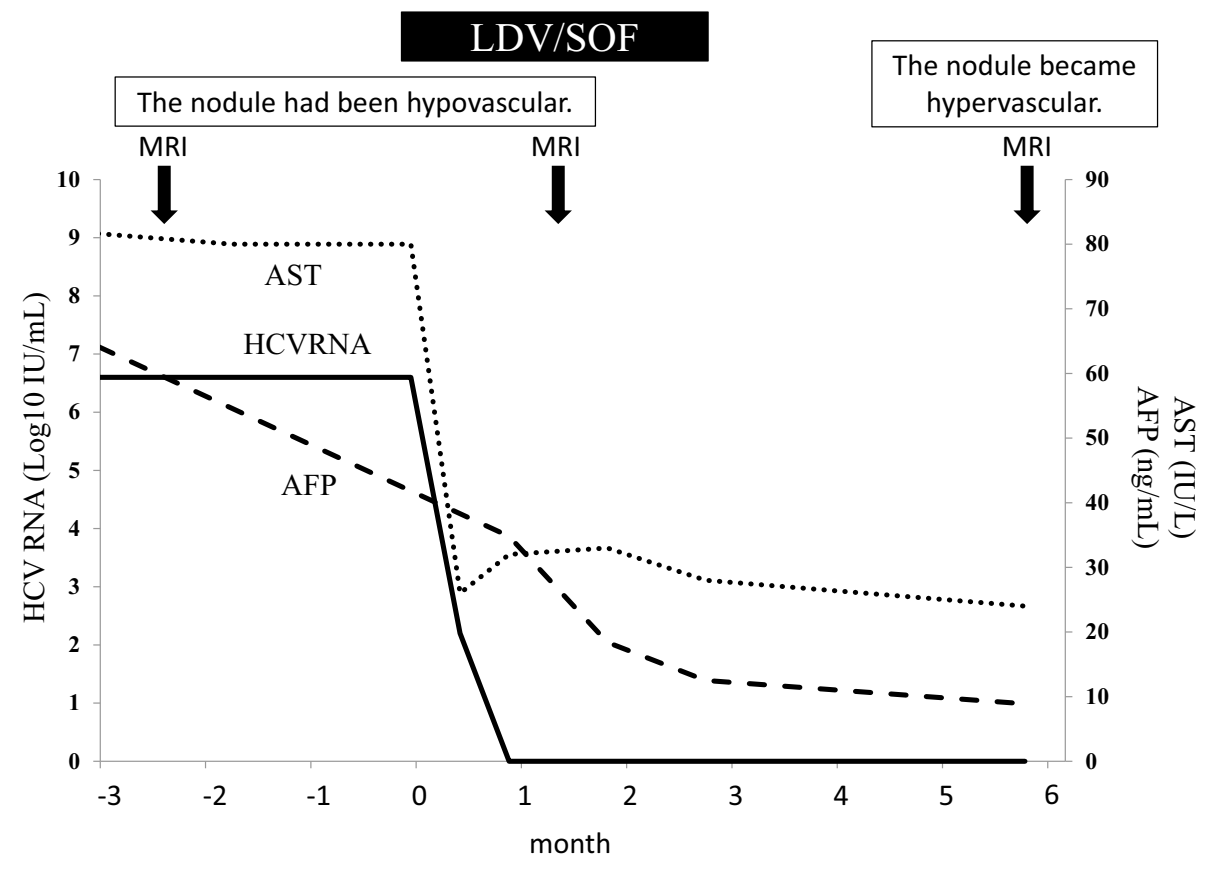

Figure 5. Clinical course of Case 2. LDV/SOF: ledipasvir/sofosbuvir

before the initiation of DAA treatment (Fig. 4c and d), and during the course of DAA treatment (Fig. 4e and f). She underwent radiofrequency ablation of the lesion and has survived without recurrence for 12 months.

\section{Discussion}

DAA treatment leads to an extremely high SVR rate against $\mathrm{HCV}$ infection, and a reduction in the incidence of $\mathrm{HCV}$-related HCC is anticipated in the future. Unexpectedly, however, a high rate of HCC recurrence following antiviral treatment using DAA was recently reported $(1,2)$. Reig et al. (1) reported that, of 58 patients with prior HCC who received DAAs, 16 (27.6\%) developed radiologic tumor recurrence after a median follow-up of 5.7 months. Conti et al. (2) reported that, of 344 consecutive cirrhotic patients without HCC treated with DAAs, HCC was detected in 17 of 59 patients $(28.8 \%)$ with previous $\mathrm{HCC}$ and 9 of 285 patients $(3.2 \%)$ without previous HCC during 24-week followup. In these reports, patients with prior HCC had a high incidence of HCC recurrence even after DAA treatment. Therefore, strict follow-up is important after achieving an SVR. Furthermore, Conti et al. (2) reported that a few patients without prior HCC developed HCC within a short period of time. These reports suggest that DAA treatment might promote hepatocarcinogenesis.

However, there are two reports that DAA treatment does not increase the risk of $\mathrm{HCC}$ recurrence $(5,6)$. The ANRS collaborative study group on HCC reported that there is no increased risk of HCC recurrence after DAA treatment: the rates of recurrence were similar between treated and untreated patients (5). Nagata et al. (6) reported that the risks of early HCC occurrence and recurrence after viral eradication were similar between IFN-based and DAA treatment.
Based on these reports, it was suggested that DAA treatment does not promote hepatocarcinogenesis. Occurrence or recurrence of HCC during or just after DAA treatment is considered a possibility if precancerous lesions or early HCC existed before DAA treatment and became obvious in the natural course.

To investigate the effect of preventing hepatocarcinogenesis with DAA treatment, it is important to compare the effects of DAA with those of IFN. In a meta-analysis by Morgan et al. (7), the SVR after IFN treatment among HCVinfected patients at any stage of fibrosis was associated with reduced HCC. In addition to antiviral actions, IFN has antitumor and immunomodulating effects, and IFN-stimulated genes (ISGs) induced by IFN play an important role in preventing carcinogenesis. Unlike IFN, however, the direct antitumor effects of DAA are unknown. Serti et al. (8) reported that the functions of ISGs and natural killer cells (NK cells) are normalized because of the rapid clearance of HCV by DAA treatment. Therefore, unexpected hepatocarcinogenesis may occur sporadically during and immediately after DAA treatment as a result of attenuation of the antitumor activities of ISGs and NK cells during HCV infection. Case 1 in our study developed HCC, $1.7 \mathrm{~cm}$ in diameter, during DAA treatment, although there were no findings of $\mathrm{HCC}$ before treatment. Case 2 developed HCC in which a hypovascular nodule that had not changed in size for 10 years became hypervascular throughout with no increase in size immediately after DAA treatment. In these cases, the occurrence of HCC and the change in the vascularity of the nodule were observed within an extremely short period after completing DAA treatment. Therefore, it was considered that rapid changes in antitumor activities induced by the rapid clearance of $\mathrm{HCV}$ led to hepatocarcinogenesis in these cases. Further investigation is needed in future studies to address 
this important question.

Several reports have revealed that male gender, older age, and liver fibrosis are significant risk factors for developing HCC after achieving an SVR (9-12). Older age and hepatic fibrosis were also refractory factors in IFN treatment. Although an SVR can be easily obtained in these refractory cases with the increased use of DAAs, more attention must be paid to the onset of HCC after achieving an SVR. Diabetes mellitus (13) and hepatic steatosis (14) are also associated with hepatocarcinogenesis after achieving an SVR. These risk factors will become more important with the increasing rate of metabolic syndrome. In addition, the alphafetoprotein (AFP) value after IFN treatment is associated with the HCC incidence (15-17). Our group (15) reported that the incidence of HCC is significantly reduced in individuals with mean AFP integration values $<10 \mathrm{ng} / \mathrm{mL}$ after IFN therapy, suggesting that the decrease in AFP by IFN therapy is a surrogate marker of the prevention of HCC. Asahina et al. (16) also reported that post-IFN treatment AFP levels are strictly associated with the risk for hepatocarcinogenesis in patients with $\mathrm{HCV}$ infection, and the cutoff value for AFP is $6.0 \mathrm{ng} / \mathrm{mL}$. Similar to IFN treatment, AFP values decrease after DAA treatment $(18,19)$. Therefore, it is necessary to investigate whether or not the low levels of AFP after DAA treatment can be a surrogate marker for preventing HCC. Because many cases treated with DAA are at a high risk of carcinogenesis, clarifying the risk factors for post-SVR carcinogenesis, including AFP levels, is necessary to perform efficient follow-up of cases after they have obtained an SVR.

In conclusion, Case 1 developed HCC immediately after DAA treatment despite the absence of evidence of HCC before treatment, and Case 2 developed HCC in which a hypovascular nodule that had not changed for 10 years became hypervascular immediately after DAA treatment. As both cases were elderly patients with progression of fibrosis, they were at a relatively high risk of hepatocarcinogenesis. Hepatocarcinogenesis may have incidentally overlapped with the treatment period. There is no consensus on the adequate surveillance period in patients who have achieved an SVR, and further investigations are needed in order to address how long observation should be performed before the risk of hepatocarcinogenesis can be deemed eliminated. Although the association between DAA treatment and hepatocarcinogenesis is not clear, sufficient surveillance after achieving an SVR is required because a large number of patients treated with DAA are at a high risk for hepatocarcinogenesis.

The authors state that they have no Conflict of Interest (COI).

\section{References}

1. Reig M, Mariño Z, Perelló C, et al. Unexpected high rate of early tumor recurrence in patients with $\mathrm{HCV}$-related HCC undergoing interferon-free therapy. J Hepatol 65: 719-726, 2016.

2. Conti F, Buonfiglioli F, Scuteri A, et al. Early occurrence and re- currence of hepatocellular carcinoma in HCV-related cirrhosis treated with direct-acting antivirals. J Hepatol 65: 727-733, 2016.

3. Uchida Y, Kouyama J, Naiki K, Mochida S. A novel simple assay system to quantify the percent HCV-RNA levels of NS5A Y93H mutant strains and Y93 wild-type strains relative to the total HCVRNA levels to determine the indication for antiviral therapy with NS5A inhibitors. PLoS One 9: e112647, 2014.

4. Narimatsu H. Development of M2BPGi: a novel fibrosis serum glyco-biomarker for chronic hepatitis/cirrhosis diagnostics. Expert Rev Proteomics 12: 683-693, 2015.

5. ANRS collaborative study group on hepatocellular carcinoma (ANRS CO22 HEPATHER COCaCCcEaspaf). Lack of evidence of an effect of direct-acting antivirals on the recurrence of hepatocellular carcinoma: data from three ANRS cohorts. J Hepatol 65: 734-740, 2016.

6. Nagata H, Nakagawa M, Asahina $Y$, et al. Effect of interferonbased and -free therapy on early occurrence and recurrence of hepatocellular carcinoma in chronic hepatitis C. J Hepatol 67: 933939, 2017.

7. Morgan RL, Baack B, Smith BD, Yartel A, Pitasi M, Falck-Ytter $Y$. Eradication of hepatitis $\mathrm{C}$ virus infection and the development of hepatocellular carcinoma: a meta-analysis of observational studies. Ann Intern Med 158: 329-337, 2013.

8. Serti E, Chepa-Lotrea X, Kim YJ, et al. Successful interferon-free therapy of chronic hepatitis $\mathrm{C}$ virus infection normalizes natural killer cell function. Gastroenterology 149: 190-200, 2015.

9. Hiramatsu N, Oze T, Takehara T. Suppression of hepatocellular carcinoma development in hepatitis $\mathrm{C}$ patients given interferonbased antiviral therapy. Hepatol Res 45: 152-161, 2015.

10. Makiyama A, Itoh Y, Kasahara A, et al. Characteristics of patients with chronic hepatitis $\mathrm{C}$ who develop hepatocellular carcinoma after a sustained response to interferon therapy. Cancer 101: 16161622, 2014.

11. Asahina $Y$, Tsuchiya $K$, Tamaki $\mathrm{N}$, et al. Effect of aging on risk for hepatocellular carcinoma in chronic hepatitis $\mathrm{C}$ virus infection. Hepatology 52: 518-527, 2010.

12. Nagaoki Y, Aikata H, Nakano N, et al. Development of hepatocellular carcinoma in patients with hepatitis $\mathrm{C}$ virus infection who achieved sustained virological response following interferon therapy: a large-scale, long-term cohort study. J Gastroenterol Hepatol 31: 1009-1015, 2016.

13. Hung $\mathrm{CH}$, Lee $\mathrm{CM}$, Wang $\mathrm{JH}$, et al. Impact of diabetes mellitus on incidence of hepatocellular carcinoma in chronic hepatitis $\mathrm{C}$ patients treated with interferon-based antiviral therapy. Int J Cancer 128: 2344-2352, 2011.

14. Kurosaki M, Hosokawa T, Matsunaga $K$, et al. Hepatic steatosis in chronic hepatitis $\mathrm{C}$ is a significant risk factor for developing hepatocellular carcinoma independent of age, sex, obesity, fibrosis stage and response to interferon therapy. Hepatol Res 40: 870-877, 2010.

15. Osaki Y, Ueda Y, Marusawa H, et al. Decrease in alpha-fetoprotein levels predicts reduced incidence of hepatocellular carcinoma in patients with hepatitis $\mathrm{C}$ virus infection receiving interferon therapy: a single center study. J Gastroenterol 47: 444-451, 2012.

16. Asahina $Y$, Tsuchiya $K$, Nishimura T, et al. $\alpha$-fetoprotein levels after interferon therapy and risk of hepatocarcinogenesis in chronic hepatitis C. Hepatology 58: 1253-1262, 2013.

17. Oze T, Hiramatsu N, Yakushijin T, et al. Post-treatment levels of $\alpha$-fetoprotein predict incidence of hepatocellular carcinoma after interferon therapy. Clin Gastroenterol Hepatol 12: 1186-1195, 2014.

18. Kobayashi M, Suzuki F, Fujiyama S, et al. Sustained virologic response by direct antiviral agents reduces the incidence of hepatocellular carcinoma in patients with $\mathrm{HCV}$ infection. J Med Virol 89: 476-483, 2017.

19. Nguyen K, Jimenez M, Moghadam N, et al. Decrease of alpha- 
fetoprotein in patients with cirrhosis treated with direct-acting Antivirals. J Clin Transl Hepatol 5: 43-49, 2017.
The Internal Medicine is an Open Access journal distributed under the Creative Commons Attribution-NonCommercial-NoDerivatives 4.0 International License. To view the details of this license, please visit (https://creativecommons.org/licenses/ by-nc-nd/4.0/).

(C) 2019 The Japanese Society of Internal Medicine

Intern Med 58: 225-231, 2019 